\title{
Data accuracy in the Ontario birth Registry: a chart re-abstraction study
}

\author{
Sandra Dunn ${ }^{1,2,3^{*}} \mathbb{D}$, Andrea Lanes ${ }^{1,2,3}$, Ann E. Sprague ${ }^{1,2,3}$, Deshayne B. Fell ${ }^{2,3}$, Deborah Weiss ${ }^{1,3}$, Jessica Reszel ${ }^{1,2}$ \\ Monica Taljaard ${ }^{3,4}$, Elizabeth K. Darling ${ }^{5}$, lan D. Graham ${ }^{3,4}$, Jeremy M. Grimshaw ${ }^{3,4}$, JoAnn Harrold 2,3,4,6,7, \\ Graeme N. Smith ${ }^{8}$, Wendy Peterson ${ }^{3}$ and Mark Walker ${ }^{1,3,4,7}$
}

\begin{abstract}
Background: Ontario's birth Registry (BORN) was established in 2009 to collect, interpret, and share critical data about pregnancy, birth and the early childhood period to facilitate and improve the provision of healthcare. Since the use of routinely-collected health data has been prioritized internationally by governments and funding agencies to improve patient care, support health system planning, and facilitate epidemiological surveillance and research, high quality data is essential. The purpose of this study was to verify the accuracy of a selection of data elements that are entered in the Registry.

Methods: Data quality was assessed by comparing data re-abstracted from patient records to data entered into the Ontario birth Registry. A purposive sample of 10 hospitals representative of hospitals in Ontario based on level of care, birth volume and geography was selected and a random sample of 100 linked mother and newborn charts were audited for each site. Data for 29 data elements were compared to the corresponding data entered in the Ontario birth Registry using percent agreement, kappa statistics for categorical data elements and intra-class correlation coefficients (ICCS) for continuous data elements.

Results: Agreement ranged from 56.9 to $99.8 \%$, but $76 \%$ of the data elements (22 of 29) had greater than $90 \%$ agreement. There was almost perfect (kappa 0.81-0.99) or substantial (kappa 0.61-0.80) agreement for 12 of the categorical elements. Six elements showed fair-to-moderate agreement (kappa <0.60). We found moderate-toexcellent agreement for four continuous data elements (ICC >0.50).

Conclusion: Overall, the data elements we evaluated in the birth Registry were found to have good agreement with data from the patients' charts. Data elements that showed moderate kappa or low ICC require further investigation.
\end{abstract}

Keywords: Data accuracy, Re-abstraction, Data quality assessment, BORN Ontario

\section{Background}

Ontario's province-wide birth Registry (Better Outcomes Registry \& Network [BORN Ontario]) was established in 2009 to collect, interpret, and share critical data about pregnancy, birth and the early childhood period. As a prescribed Registry under provincial privacy legislation, BORN Ontario safeguards data while making information available to facilitate and improve the provision of healthcare.

\footnotetext{
* Correspondence: sdunn@bornontario.ca

${ }^{1}$ Better Outcomes Registry \& Network, Ottawa, Ontario, Canada

${ }^{2}$ Children's Hospital of Eastern Ontario Research Institute, Ottawa, Ontario,

Canada

Full list of author information is available at the end of the article
}

The BORN Registry, an Internet-based data collection system, was launched in January 2012, but historical perinatal data are available from 2006 from a preexisting data collection platform. Sourced from hospitals, labs, midwifery practice groups and clinical programs, the data are either manually entered by hospital staff or uploaded directly from hospitals' electronic medical records. The scope of the data spans the antepartum, intrapartum, and postpartum periods and includes information on maternal demographics and health behaviours, pre-existing maternal health problems, pregnancy and obstetric complications, intrapartum interventions, and birth and newborn outcomes. These data are

(c) The Author(s). 2019 Open Access This article is distributed under the terms of the Creative Commons Attribution 4.0 International License (http://creativecommons.org/licenses/by/4.0/), which permits unrestricted use, distribution, and reproduction in any medium, provided you give appropriate credit to the original author(s) and the source, provide a link to the Creative Commons license, and indicate if changes were made. The Creative Commons Public Domain Dedication waiver (http://creativecommons.org/publicdomain/zero/1.0/) applies to the data made available in this article, unless otherwise stated. 
captured at the time of birth from medical records, clinical forms, and patient interviews for all hospitals births as well as home and birth centre births in Ontario. With nearly $40 \%$ of all live births in Canada occurring in Ontario (36.7\% in 2016) [1], this database is a rich source of perinatal information for a large proportion of the births in Canada. Data from the BORN Registry are widely used to facilitate care, support clinicians, inform policy makers, and conduct research to increase knowledge about optimal care [2-16].

This relatively new system uses a complex method of collecting data at the different points during pregnancy, birth and into childhood, often collecting the same data element multiple times throughout the course of care. These data are then brought together to form a unified maternalnewborn record using robust linking and matching algorithms. Duplicated data elements from multiple care encounters are also aggregated through a complex set of decision rules into the final unified record in the Registry. Each contributing site has access to their own data through a robust and secure reporting portal and BORN Ontario reports on outcomes aggregated at the provincial level at regular intervals [17-21].

Since the use of routinely-collected health data has been prioritized internationally by governments and funding agencies to improve patient care, support health system planning and health care efficiency, facilitate epidemiological surveillance, and transform research, access to high quality data is essential $[22,23]$. Formal processes for regular data validation, quality checks, and training for individuals entering and using the data have been implemented to support a high level of data quality $[24,25]$. However, as with any administrative dataset, these data may be vulnerable to random and systematic errors due to incomplete or illegible documentation in the patient health record, human error during manual data entry, electronic health record upload errors, unclear definitions, or inadequately trained personnel [24]. Given the complex nature of the data collected in the Registry, the objective of our study was to assess the accuracy of a subset of core data elements by conducting a complete reabstraction audit comparing data entered into the BORN Registy with data from the patient health record. This paper reports the results of the study.

\section{Methods}

\section{Theoretical framework}

We used the data quality framework adopted by BORN Ontario which is based on five dimensions: timeliness, accuracy (validity), comparability (reliability), usability and relevance to guide this study [25, 26]. Additionally, we followed similar methods to those described by other re-abstraction studies such as the Data Quality Assessment of the Niday Perinatal Database [24], the Canadian Institute for Health Information (CIHI) Data Re-
Abstraction Study (2015-2016) [27], and the British Columbia Perinatal Data Registry re-abstraction study [28]. The re-abstraction process is outlined in Fig. 1.

\section{Ethics and privacy issues}

This re-abstraction study was a quality assurance project, and therefore exempt from Research Ethics Board review under article 2.5 of the Tri-council Policy Statement [29]. Hospital participation was voluntary, and confidentiality of patient information and privacy of participating hospitals was maintained. The auditors reentered data from the patient records that had previously been entered by the hospital personnel into the Registry. The re-abstracted electronic data were entered into a secure online data capture system, Research Electronic Data Capture (REDCap) [30], and then stored and analyzed on a secure network drive. All data were aggregated, and findings were anonymized.

\section{Site recruitment, record selection, and creation of a re- abstraction tool}

We recruited participant hospitals from different health regions in the province. We aimed to have representation from all levels of care, geographic regions, and different data entry methods (i.e., manual entry versus electronic upload). Selected sites were provided with information about the project and invited to participate. For those that agreed to participate, the appropriate permissions to undertake a data quality assessment and allow our data auditors access to patient charts were obtained.

We selected a subset of data elements $(n=29)$ from the Registry for re-abstraction based on the following criteria: a) data element was used in the computation of key performance indicators in BORN Ontario's Maternal Newborn Dashboard [5]; and b) data element was prioritized for validation by the BORN Data Quality Team based on operational requirements for reporting and research (e.g., maternal height and weight used to calculate Body Mass Index (BMI) and maternal smoking).

We produced a computer-generated random sample of 100 maternal chart numbers (and linked baby records) for each of the 10 participating sites from existing records that had already been entered into the Registry database in 2014-15. At the time of the study there were 96 hospitals in Ontario providing maternal-newborn care with approximately 140,000 births annually. We targeted 1000 records to provide a reasonable sample size for calculating measures of agreement based on the prevalence rates of the data elements under review. This sample size was primarily based on feasibility; however, we calculated that, for an expected kappa of 0.85 , a total of 1000 records yields a two-sided $95 \%$ confidence interval with a total width of 0.111 (i.e., a lower limit of 0.80 ) if the prevalence is $90 \%$ using Fleiss's large-sample 


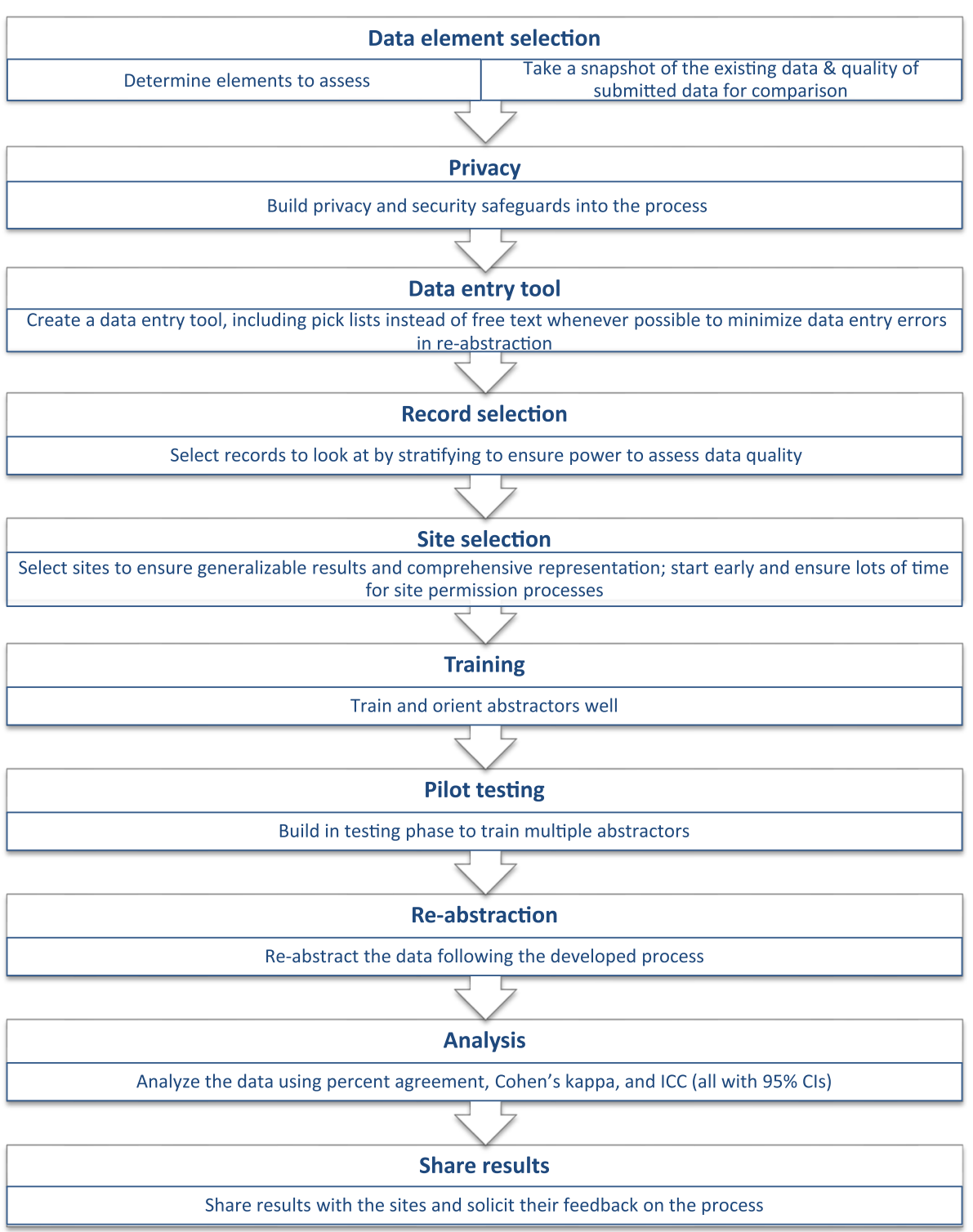

Fig. 1 BORN re-abstraction process

formula. If the prevalence is lower, say $50 \%$, the total width narrows to 0.065 (lower limit of 0.82 ). These margins of error were considered acceptable by the team.

A list of the chart numbers for reabstraction was sent via a secure messaging system to the hospital liaison for each site, to obtain access to the charts for the auditors. A data abstraction tool was prepared using REDCap [31]. REDCap allowed for data validation and cleaner data structuring of abstracted data, but also for the creation of a screen specific to a given entered record.

\section{Abstractor orientation}

Two experienced auditors conducted the on-site audits. As a part of the auditor training, we created a detailed definition for each of the data elements to be re- abstracted, based on the current documentation available to those entering Registry data. We then consulted with clinical experts to determine a hierarchy of chart documentation, so that the abstractors could choose between conflicting information that may be recorded in different sections of the chart.

At each site, the auditors received basic, standardized orientation to the hospital-specific data entry systems and practices, and were trained to obtain information from the same sources used for the original data entry (e.g., the admission record, the provincial antenatal record, the labour and birth record, the discharge summary, lab results, etc.). Each auditor was given access to an online REDCap file with pre-entered blinded chart numbers for each site. 
For inter-rater reliability, both auditors re-entered data into REDCap from all 100 paired mother-baby charts from the first site. This was done in three stages with comparison and discrepancy resolution after each stage to help auditors learn and improve their process. Once they had completed the first 50 charts, the results were compared and the percent agreement and inter-rater reliability was calculated. The project team then discussed discrepancies and developed a consistent approach for data collection for these elements. The auditors then went back and corrected records where there had been errors and independently audited an additional 20 records. Agreement between the auditors was reassessed, discrepancies were discussed, data captured in REDCap were again corrected and the final group of records was re-abstracted. Auditor agreement on the final portion of records reviewed was above 95\% for all data elements abstracted. Outstanding discrepancies between the auditors were discussed and corrected for this final section of data.

Once the agreement between the auditors met our threshold (95\%), they began re-abstracting data from the additional sites recruited for the audit (one auditor per chart). While this process was ongoing, a log of changes and anomalies from different sites was created to document changes and deviations from the protocol that occurred.

\section{Data collection}

Data re-abstraction took place from August to November, 2015. The charts (paper or electronic records) were obtained from the Health Records Departments of each of the participating hospitals. The auditors re-abstracted the data into the REDCap data entry forms, which included drop-down menus matching those found in the Registry database's entry screen. For ease of data entry, the data elements were placed in the same order as they appeared in the majority of hospital records. Data were entered using laptop computers and a secure logon to REDCap.

\section{Data analysis}

We imported the re-abstracted chart data from REDCap into SAS (version 9.4) for analysis, where they were merged with the original data entered into the Registry database. We used percent agreement, Cohen's kappa statistic ( $\mathrm{k}$ ) for binary data and intraclass correlation coefficient (ICC) for continuous data [32] to compare the data re-abstracted from patient records with data previously entered into the Registry. We did not impute any values, thus, if data were missing in one or the other source, this was considered a disagreement. If data were clinically relevant and missing in both data sources, then this was considered to be an agreement.

\section{Categorical data elements}

All categorical/nominal data elements were analyzed using two-way cross tabulations and Cohen's kappa statistic to examine the proportion of responses in agreement in relation to the proportion of responses that would be expected by chance, given symmetrical marginal distributions [33-35]. Cohen's kappa statistic represents the proportion of agreements after accounting for chance agreement. Kappa values range from 0 (no agreement) to 1 (total agreement). A kappa value of 0.90, for example, indicates almost perfect agreement while a kappa value of less than 0.60 reflects only moderate agreement [36].

\section{Continuous data elements}

For continuous data elements, we assessed raw percent agreement using an equal/not equal statement. Additionally, we calculated an ICC which is a more appropriate measure of reliability for continuous data than Pearson's product moment correlation coefficient or Spearman's rank-order correlation coefficient since these measure association rather than agreement [33]. ICC values range between 0 (no agreement) and 1 (total agreement) [37]. An ICC over 0.90, for example, indicates excellent agreement, while an ICC less than 0.50 indicates poor agreement between data elements [38]. The notes below Table 1 provide more detailed interpretation of kappa and ICC values.

\section{Results}

Ten hospitals from across Ontario participated: two from the 47 Level 1 hospitals; six from the 41 Level 2 hospitals; and two from the eight Level 3 hospitals. A combination of both paper and electronic documentation systems and a variety of data entry processes were used by the sample hospitals. The total number of charts re-abstracted for this project was 927 linked mother/ baby records (Fig. 2). We did not achieve the full target of 1000 charts because some of the requested patient charts were not available during the re-abstraction period.

A total of 29 data elements were re-abstracted from patient records to assess the degree of agreement with data already in the Registry. The overall results are summarized in Fig. 3 (percent agreements) and Table 1 (percent agreements, Cohen's kappa or ICC). Of the 29 data elements (21 categorical and 8 continuous) reabstracted, 22 (75.9\%) showed $>90 \%$ agreement, suggesting that these data elements may be used with confidence.

Of those categorical data elements with $>90 \%$ agreement, four had kappa values $>0.80$ indicating almost perfect agreement (beyond chance) (type of birth, whether there were indications for cesarean section, labour and 
Table 1 Percent agreement, Cohen's kappa and intra-class correlation coefficient (ICC) for re-absracted data elements

\begin{tabular}{|c|c|c|c|c|c|c|}
\hline Data Element & Coding & Matched n/927 (\%) & Kappa (к) (\%) & $95 \% \mathrm{Cl}$ & ICC (\%) & $95 \% \mathrm{Cl}$ \\
\hline \multicolumn{7}{|l|}{ SITE ID } \\
\hline \multicolumn{7}{|l|}{ Maternal chart ID } \\
\hline \multicolumn{7}{|l|}{ Baby chart ID } \\
\hline 1. Episiotomy ${ }^{\mathrm{d}}$ & $\begin{array}{l}\text { None } \\
\text { Medio-lateral } \\
\text { Midline } \\
\text { Medial } \\
\text { Unknown }\end{array}$ & $847(91.4)$ & 0.67 & $0.61-0.73$ & & \\
\hline $\begin{array}{l}\text { 2. Diabetes and Pregnancy (17 possible } \\
\text { pick list choices - MS }{ }^{b} \text { ) }\end{array}$ & $\begin{array}{l}\text { Yes } \\
\text { No } \\
\text { Unknown }\end{array}$ & $855(92.2)$ & 0.79 & $0.72-0.86$ & & \\
\hline 3. Intention to breastfeed & $\begin{array}{l}\text { Yes } \\
\text { No }\end{array}$ & $757(81.7)$ & 0.30 & $0.22-0.37$ & & \\
\hline 4. Newborn feeding at discharge & $\begin{array}{l}\text { Formula only } \\
\text { Combination } \\
\text { Breastmilk only } \\
\text { Not applicable } \\
\text { Other } \\
\text { Unknown }\end{array}$ & $706(76.2)$ & 0.68 & $0.64-0.73$ & & \\
\hline 5. Newborn discharged or transferred to ${ }^{d}$ & $\begin{array}{l}\text { Home } \\
\text { Child and family services } \\
\text { apprehension } \\
\text { Transfer to NICU/SCN other } \\
\text { hospital } \\
\text { Transfer to NICU/SCN same } \\
\text { hospital } \\
\text { Transfer to pediatric unit }\end{array}$ & $859(92.7)$ & 0.46 & $0.25-0.68$ & & \\
\hline 6. Hypertension during pregnancy & $\begin{array}{l}\text { None } \\
\text { Eclampsia } \\
\text { Gestational hypertension } \\
\text { HELLP } \\
\text { Preeclampsia } \\
\text { Pre-existing hypertension with } \\
\text { superimposed preeclampsia } \\
\text { Unknown }\end{array}$ & $893(96.3)$ & 0.58 & $0.46-0.70$ & & \\
\hline 7. Group B Strep screening results & $\begin{array}{l}\text { Done, negative result } \\
\text { Done, positive result } \\
\text { Result unknown } \\
\text { Urine positive for GBS } \\
\text { Not done } \\
\text { Unknown if screened }\end{array}$ & $739(79.7)$ & 0.75 & $0.71-0.79$ & & \\
\hline $\begin{array}{l}\text { 8. Group B Strep screening not done } \\
\text { reason }{ }^{\mathrm{a}}\end{array}$ & $\begin{array}{l}\text { Declined screening } \\
\text { Other } \\
\text { Previous baby with GBS disease } \\
\text { Urine positive for GBS }\end{array}$ & $880(94.9)$ & & & & \\
\hline 9. Labour type ${ }^{d}$ & $\begin{array}{l}\text { Spontaneous } \\
\text { Induced } \\
\text { No labour }\end{array}$ & $908(98)$ & 0.61 & $0.57-0.65$ & & \\
\hline $\begin{array}{l}\text { 10. Mother resides with cigarette smoker at } \\
\text { time of prenatal visit }\end{array}$ & $\begin{array}{l}\text { Yes } \\
\text { No } \\
\text { Unknown }\end{array}$ & $914(98.6)$ & 0.68 & $0.64-0.71$ & & \\
\hline $\begin{array}{l}\text { 11. Mother resides with cigarette smoker at } \\
\text { time of labour /admission }\end{array}$ & $\begin{array}{l}\text { Yes } \\
\text { No } \\
\text { Unknown }\end{array}$ & $780(84.1)$ & 0.67 & $0.64-0.71$ & & \\
\hline $\begin{array}{l}\text { 12. Maternal cigarette smoking at prenatal } \\
\text { visit }\end{array}$ & $\begin{array}{l}\text { None } \\
<10 / \text { day } \\
10-20 / \text { day } \\
>20 / \text { day } \\
\text { Unknown }\end{array}$ & $835(90.1)$ & 0.56 & $0.49-0.62$ & & \\
\hline 13. Maternal cigarette smoking at time of & None & $726(78.3)$ & 0.58 & $0.50-0.65$ & & \\
\hline
\end{tabular}


Table 1 Percent agreement, Cohen's kappa and intra-class correlation coefficient (ICC) for re-absracted data elements (Continued)

\begin{tabular}{|c|c|c|c|c|c|c|}
\hline Data Element & Coding & Matched n/927 (\%) & Kappa (к) (\%) & $95 \% \mathrm{Cl}$ & ICC (\%) & $95 \% \mathrm{Cl}$ \\
\hline labour $^{d}$ & $\begin{array}{l}<10 / \text { day } \\
10-20 / \text { day } \\
>20 / \text { day } \\
\text { Unknown }\end{array}$ & & & & & \\
\hline 14. Type of birth ${ }^{d}$ & $\begin{array}{l}\text { Spontaneous vaginal } \\
\text { Assisted vaginal } \\
\text { Induced or spontaneous labour CS } \\
\text { No labour CS }\end{array}$ & $876(94.5)$ & 0.89 & $0.79-1.00$ & & \\
\hline $\begin{array}{l}\text { 15. Indications for caesarean section ( } 28 \\
\text { possible pick list choices - MS })^{d}\end{array}$ & $\begin{array}{l}\text { Yes } \\
\text { No }\end{array}$ & $901(97.2)$ & 0.92 & $0.89-0.95$ & & \\
\hline $\begin{array}{l}\text { 16. Maternal Health Conditions ( } 79 \text { possible } \\
\text { pick list choices - MS } \text { ) }\end{array}$ & $\begin{array}{l}\text { Yes } \\
\text { No }\end{array}$ & $916(98.8)$ & 0.75 & $0.61-0.89$ & & \\
\hline $\begin{array}{l}\text { 17. Complications of Pregnancy ( } 24 \\
\text { possible pick list choices }-\mathrm{MS}^{\mathrm{b}} \text { ) }\end{array}$ & $\begin{array}{l}\text { Yes } \\
\text { No }\end{array}$ & $918(99)$ & 0.79 & $0.65-0.92$ & & \\
\hline $\begin{array}{l}\text { 18. Pain relief measures during newborn } \\
\text { screening or serum bilirubin }\end{array}$ & $\begin{array}{l}\text { Breastfeeding } \\
\text { Skin to Skin } \\
\text { Sucrose } \\
\text { Other } \\
\text { None } \\
\text { Unknown }\end{array}$ & $834(90)$ & 0.50 & $0.41-0.59$ & & \\
\hline $\begin{array}{l}\text { 19. Labour and birth complications ( } 21 \\
\text { possible pick list choices }- \text { MS }^{b} \text { ) }\end{array}$ & $\begin{array}{l}\text { Yes } \\
\text { No }\end{array}$ & $913(98.5)$ & 0.88 & $0.81-0.94$ & & \\
\hline $\begin{array}{l}\text { 20. Indications for induction of labour ( } 23 \\
\text { possible pick list choices - MS })^{\text {d }}\end{array}$ & $\begin{array}{l}\text { Yes } \\
\text { No }\end{array}$ & $851(91.8)$ & 0.76 & $0.70-0.80$ & & \\
\hline 21. Fetal surveillance ${ }^{d}$ & $\begin{array}{l}\text { Admission EFM strip } \\
\text { Auscultation } \\
\text { Intrapartum EFM (external) } \\
\text { Intrapartum EFM (internal) } \\
\text { No monitoring } \\
\text { Unknown }\end{array}$ & $922(99.5)$ & 0.95 & $0.91-0.99$ & & \\
\hline 22. Number of fetuses ${ }^{d}$ & $\begin{array}{l}\text { Number (0-8) } \\
\text { Unknown }\end{array}$ & $925(99.8)$ & & & 0.90 & $0.89-0.91$ \\
\hline 23. Number of previous cesarean births $c, d$ & $\begin{array}{l}\text { Number (0-6) } \\
\text { Unknown }\end{array}$ & $909(98.1)$ & & & 0.63 & $0.59-0.67$ \\
\hline 24. Maternal pre-pregnancy weight & Weight & $887(95.7)$ & & & 0.82 & $0.79-0.84$ \\
\hline 25. Maternal height & Height & $925(99.8)$ & & & 0.54 & $0.50-0.59$ \\
\hline 26. Maternal weight at end of pregnancy & Weight & $924(99.7)$ & & & 0.49 & $0.44-0.55$ \\
\hline 27. Estimated date of birth & DD-MM-YYY & $605(65.3)$ & & & & \\
\hline 28. Date of birth & DD-MM-YYY & 877 (94.6) & & & & \\
\hline 29. Gestational age at birth ${ }^{c, d}$ & Weeks & $771(83.2)$ & & & & \\
\hline Gestational age at birth ${ }^{c}$ & Days & $527(56.9)$ & & & & \\
\hline
\end{tabular}

Notes: ${ }^{\text {a}}$ The cell sizes across the response options were too small to run kappas.

${ }^{\mathrm{b}}$ MS Multiselect

'Unable to report ICCS due to lack of convergance of algorithm

${ }^{\mathrm{d}}$ Data elements evaluated in the Niday Perinatal Database Re-abstraction Study [24]

Cohen's kappa statistic $(\mathrm{K})$ - degrees of agreement after chance agreement has been excluded [36]: Poor $<0$; Slight $=0-0.20 ;$ Fair $=0.21-0.40 ;$ Moderate $=0.41-$

0.60 ; Substantial $=0.61-0.80$; Almost perfect $=0.81-0.99$

Intra-class correlation coefficient (ICC) [38]: Poor <0.50; Moderate $=0.50-0.75$; Good $=>0.75-0.90$; Excellent $>0.90$

birth complications, and fetal surveillance type). Seven categorical data elements had kappa values from 0.610.80 demonstrating substantial agreement (beyond chance) (labour type, mother resides with smoker at first prenatal visit, maternal health conditions, complications of pregnancy, diabetes in pregnancy, episiotomy, and indications for induction). There were four categorical data elements with high agreement (>90\%), but kappa values $<0.60$ (suggesting agreement could have been due to chance), that warrant further investigation (hypertension during pregnancy, location newborn discharged/transferred to, maternal smoking at first prenatal visit, and pain relief for the newborn). Five of the 21 categorial data elements demonstrated $<85 \%$ agreement and need 


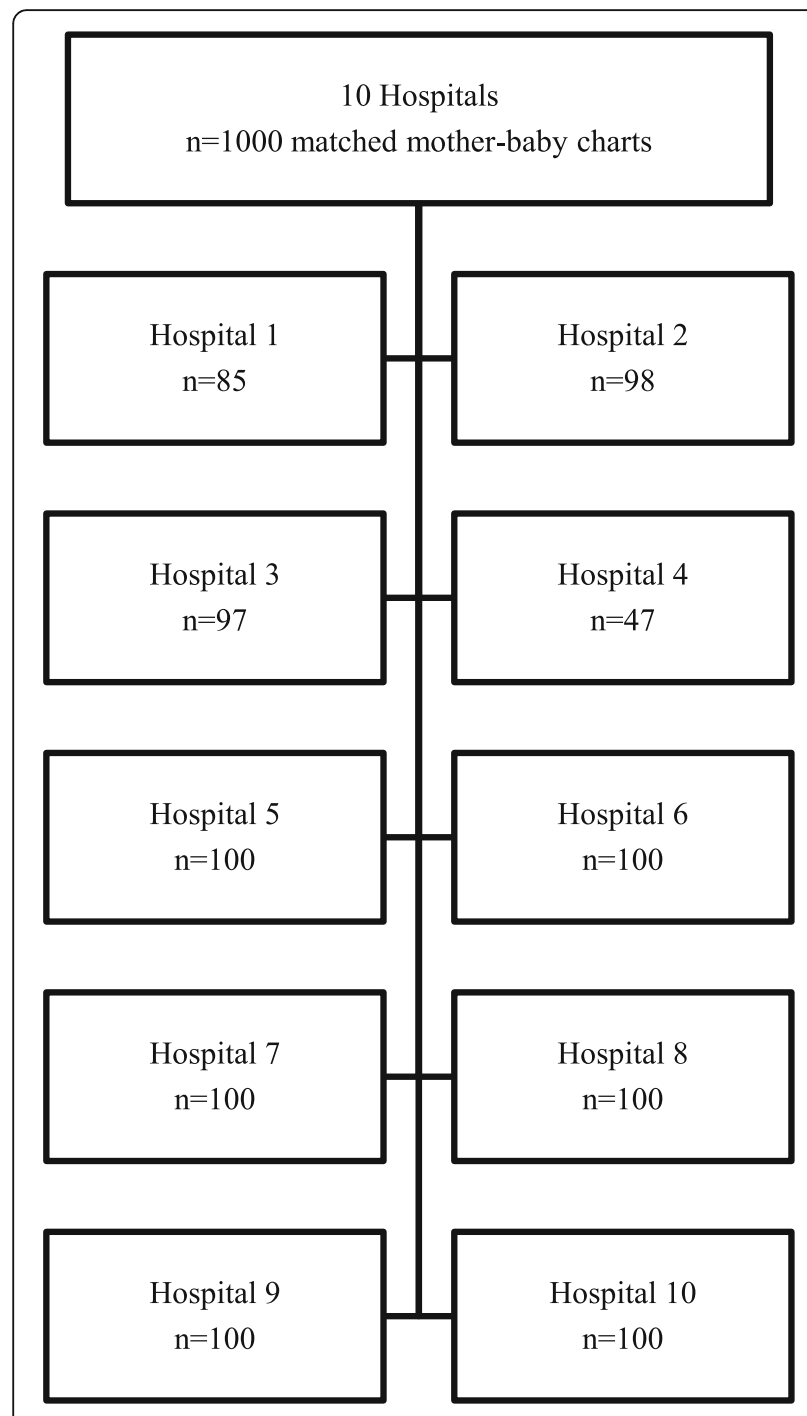

Fig. 2 Flow diagram of charts included

further investigation (intention to breastfeed, newborn feeding at discharge, Group B Streptococcus screening results, mother resides with a smoker at time of labour/admission, and maternal smoking at time of labour/ admission).

Of the eight continuous data elements re-abstracted, six had agreement $>90 \%$ (number of fetuses, number of previous cesarean births, maternal pre-pregnancy weight, maternal height, maternal weight at end of pregnancy, and infant's date of birth). Of those, four elements had ICC values $>0.50$, demonstrating moderate to excellent agreement (beyond chance) (number of fetuses, maternal pre-pregnancy weight, maternal height, and number of previous cesarean births). Although there was high agreement (>90\%) for maternal weight at end of pregnancy, ICC values were $<0.50$ (suggesting agreement may have been due to chance), therefore, this data element warrants further investigation as do the data elements, estimated date of birth and gestational age at birth (weeks and days), which were found to have $<90 \%$ agreement.

\section{Discussion}

In this data re-abstraction study we found moderate-tohigh levels of agreement (beyond chance) between the data collected routinely in the Registry with data collected through this chart re-abstraction. Although neither of the datasets used during the audit can be declared as a gold standard, these results suggest that these core Registry data elements have high validity [39], as do the data elements used to define the key performance indicators in the Maternal Newborn Dashboard [5].

Although reasons for non-agreement were not always apparent, we identified a number of potential contributing factors. These include: discretionary completion of data elements during original data entry (as opposed to a compulsory data element); lack of clarity of information available in the health record; and inaccurate or duplicate documentation in the health record. First, in reviewing the non-agreements and based on feedback from the auditors, it was evident that in some cases the auditor found and entered information from the patient record that the hospital data entry person did not enter. Despite the fact that the goal for both groups was to ensure complete and accurate data entry for each case, in reality, selection of 'unknown' during original data entry for some data elements contributed to the nonagreement. Although there are validation checks and missing data reports built into the Registy, along with an extensive monthly data verification process, and BORN Coordinator support for all user organizations, this suggests there is a need for additional initiatives to ensure incomplete records are minimized and that only essential, meaningful data are collected, which would reduce redundancy in this dataset.

The second issue related to the availability of information in the patient health record. If detailed information was not documented in the patient record to match the pick list choices in the Registry, data quality was affected. For example, in the case of infant pain relief during newborn screening or bilirubin screening, documentation was not always available to capture this practice in a standardized way creating discrepancies between what was entered in the Registry and what the auditor found in the chart. This example illustrates the critical importance of aligning documentation tools with data entry processes to enhance data quality.

The third issue related to inaccurate or duplicate documentation. Data entry is dependent on the accuracy of the information recorded in the patient record. Even though specific documents were used as the source of information for data entry, some information was 


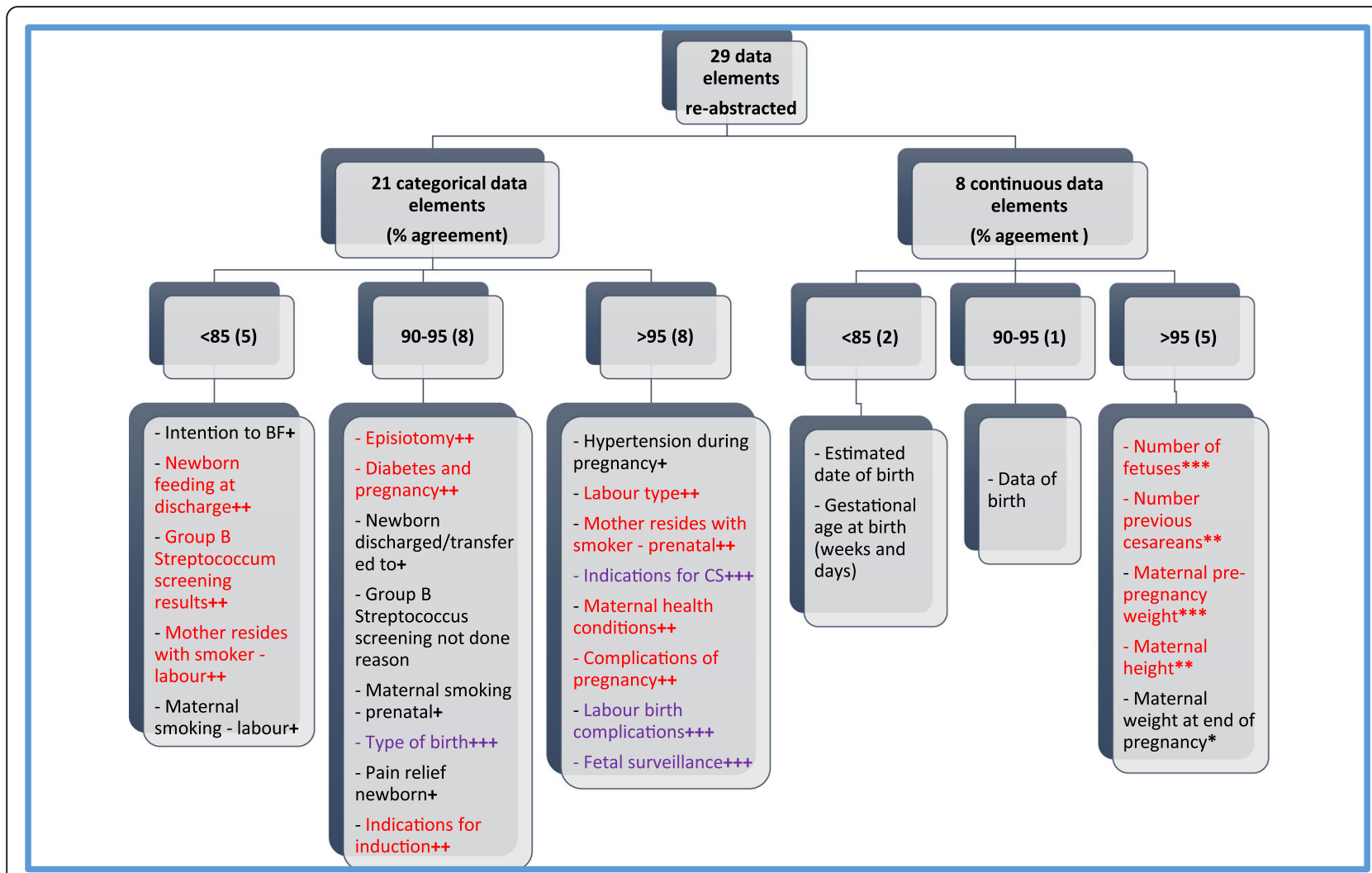

Fig. 3 Summary of results (percent agreement). Cohen's kappa statistic $(k)$ - degrees of agreement after chance agreement has been excluded (Landis \& Koch, 1977): $+\leq$ 0.60; ++ 0.61-0.80; +++ > 0.80. Intra-class correlation coefficient (ICC) (Portney \& Watkins, 2000): ${ }^{*}<0.50$; ${ }^{* *} 0.50-0.75 ;{ }^{* * *}>0.75$

difficult to find, or inconsistent, within the patient record, contributing to non-agreement. For example, with maternal weight at end of pregnancy, multiple entries of this data with differing values within the patient record may have contributed to non-agreement.

Ten of the data elements included in this reabstraction study were also evaluated as part of a validation study of the historical perinatal database (i.e., the Niday Perinatal Database audit) [24] (Table 1- see d). We assessed agreement to be consistently above $90 \%$ for eight of these data elements in both audits. One of the data elements found to be less reliable during the Niday audit - maternal smoking at the time of labour/admission (agreement 78.9\% - kappa, 0.51) [24] - was also identified in this audit as requiring further investigation (agreement 78.3\% - kappa, 0.58). The data element episiotomy, which had $82.7 \%$ agreement (kappa, 0.47 ) in the Niday audit has improved in the new Registry database, with agreement of $91.4 \%$ (kappa, 0.67) in the current audit. Other data elements such as: labour type, type of birth, indications for cesarean section, number of fetuses, and previous cesarean births, which had very high agreement and kappa values in the Niday audit, remain valid.
The practical contribution of this study is that a subset of data elements has been evaluated for accuracy and comparability with the patient health record, validating them for use by clinicians, policy makers and researchers and identifying potential issues with some data elements that need further exploration by the BORN Data Quality Team. From a Knowledge Translation (KT) perspective the results of this study will increase confidence in the accuracy of the data and build trust in the evidence produced from it.

Although most data elements can be used with confidence, we found a number of data elements to be potentially problematic. The data elements re-abstracted through this audit are all priority items for BORN and its stakeholders, and further investigation of the issues identified will be undertaken by the BORN Data Quality Team to develop strategies to improve the quality of these data elements in the Registry. Ensuring completeness and high validity of the data entered into the Registry and finding ways to enhance data quality are paramount, especially since patient care or funding decisions may be made using administrative or Registry data. The Canadian Institute for Health Information (CIHI) and other clinical registries, are all seeking similar ways 
to enhance their quality [22, 23, 27]. Based on the results of this audit, and through consultation with experts in the field, a number of recommendations have been identified to improve data quality (Table 2).

\section{Limitations}

There are limitations to this study. First, the process we used for analysis deviates from some other published data re-abstraction studies $[28,40]$ insofar as we did not declare the re-abstracted chart data to be the 'gold standard'. Although sensitivity and specificity can be used to measure the accuracy of data, comparing an external source to a primary source of data requires one of the data sources to be identified as the gold standard [41]. Many factors can affect the quality of data transferred from the patient record, such as observer variation, incomplete or illegible documentation, lack of availability and timeliness of chart completion [42], making it impossible to identify a gold standard from either the original data entered into Registry or the reabstracted data entered by the auditors. In such cases, when neither data source can be designated as the gold standard, high agreement between the two sources suggests a high degree of validity - a measure of data quality [41, 43].

Table 2 Recommendations to improve data quality

\begin{tabular}{l} 
Recommendations to Improve Data Quality \\
\hline 1. Enhance the data dictionary and data entry guidelines documents \\
to standardize collection and use of data in the Registry; \\
2. Clarify definitions (e.g., hypertension during pregnancy, location \\
discharged or transferred to, labour type); \\
3. Continue to monitor data quality in each organization; \\
4. Communicate with hospital users regularly about data quality \\
issues identified and support corrective strategies to reduce the \\
occurrence of errors; \\
5. Create site-specific audit tools for hospitals to monitor their own \\
data quality and identify potentially modifiable data quality issues that \\
could be addressed early; \\
6. Continue to encourage accurate documentation in the patient \\
health record to ensure complete information for data entry \\
personnel (e.g., newborn pain relief); \\
7. Set automatic verification checks at the time of data entry (e.g., \\
height, weight, gestational age); \\
8. Create logic checks where possible based on practice guidelines \\
(e.g., fetal surveillance); \\
9. Reassess and refine data element pick list options for problematic \\
data elements (e.g., intention to breastfeed, newborn discharged or \\
transferred to, hypertension during pregnancy, maternal smoking at \\
first prenatal visit and at labour) to align these data elements with the \\
patient health record documentation and optimize data capture; \\
10. Provide ongoing training for new staff, to ensure that all data \\
entry personnel are aware of the data elements to be entered, where \\
to find the information and how to address issues of discrepancy \\
when they occur. \\
\hline
\end{tabular}

Although we compared two data sources we cannot definitively conclude that the differences observed between the two are due to inadequacies in the Registry data, as not all data elements collected in the Registry are routinely available in the patient chart. Additionally, some sites have nursing staff enter data into the Registry in real time while providing patient care. Therefore, the person originally entering data may have much more familiarity and depth of knowledge about the clinical scenario than our abstractors. However, as the hospital chart is the official legal medical record for a patient, it should be considered the standard record of care received. From an analytical perspective, this does not influence the analyses we performed on these data; however, it does impact our interpretation of the results and the implications for improvements in the future.

Where there was disagreement and inconsistency between the two data sources, part of this difference could be due to data error in the Registry, erroneous data entered during the audit, or errors in both datasets. Error due to data entered during the audit is likely minimal given the stringent procedures followed. A prevalence effect due to asymmetrical imbalances of marginal totals may have contributed to low kappa values for some of the data elements [44]. These have been flagged for further investigation.

In addition to these larger considerations, the data abstraction tool used for this work could also be a limitation. Care must be taken to ensure the method of data capture for the re-abstracted data does not introduce additional bias. By using a data entry form in REDCap, that allowed for the entry of data only on a single patient and with built in pick list options and range requirements to facilitate accurate data collection, we were able to minimize the introduction of bias by our abstractors. Using REDCap significantly minimized the introduction of errors from our data abstraction process, as compared to using an Excel spreadsheet (as we did in previous pilot work for this process). However, the REDCap abstraction tool did not mimic the actual data entry screens in the Registry, nor, in some sites, the actual flow of data in the patient health record. As a result, the abstractors did find the flow of data entry into our abstraction tool to be a challenge at times. Given the diversity and unstandardized nature of hospital documentation systems across Ontario, it is challenging to design a tool with a data entry flow to match all possible systems. In the future, ensuring a chronological data flow for our entry tool could improve the process and further minimize errors introduced by the abstraction process.

A lesson learned from this work was the need for more rigorous data element definitions in the Registry database. Because data entry processes vary across sites (e.g., clerk-entry, nurse-entry, upload from electronic 
medical record), there is the potential for different interpretations of the way data are captured and cases are classified. This variability in data entry systems makes it difficult to assess the accuracy of certain data elements, when the source of these data or the way they were recorded varies from site to site. We intend to enhance the data dictionary and data entry guidelines available to maternal-newborn hospitals in Ontario as a deliverable of this project. This will help to facilitate a robust, rigorously developed, and standardized system of data entry across the province.

\section{Conclusions}

The accuracy of most of the data elements included in this study was very good. However, some of the data elements audited need to be strengthened and these issues will be addressed by the BORN Data Quality Team through their work to improve data definitions, enhance training for data entry personnel and review data element revisions and changes through the enhancement process. This study contributes valuable information that will help to improve the quality of BORN data, increasing trust and use of the data to facilitate quality improvement, patient care, and research.

\section{Abbreviations}

BMI: Body Mass Index; BORN: Better Outcomes Registry \& Network Ontario; CHEO: Children's Hospital of Eastern Ontario; $\mathrm{CIHI}$ : Canadian Institute for Health Information; ICC: Intra-class Correlation Coefficient; REDCap: Research Electronic Data Capture

\section{Acknowledgements \\ This project is the result of the efforts of many individuals and organizations in Ontario. We thank Erin Graves, who helped to develop the protocol for the reabstraction project, and contributed to the development of the reabstraction process and an early draft of the methods described in this manuscript; the auditors Natalie Rybak, Patti Waddell for their tireless efforts collecting data at the participating sites across the province; and the countless practitioners, data entry personnel and decision makers who provided assistance to make the project possible.}

\section{Authors' contributions}

SD and MW are co-principal investigators for the described study. SD, AES, IDG, JMG, WEP, ED, DBF, JH, GNS, MT, MW, DW and JR contributed to the conceptualization and the design of the study. AL analyzed the data. SD drafted the initial manuscript. All authors participated in the writing of this manuscript and reviewed and approved the final manuscript. The following co-authors are all Canadian Institutes of Health Research (CIHR) Foundation Scheme recipients - IG (FDN \#143237), JG (FDN \# 143269), and MW (FDN \# 148438). JG also holds a Canada Research Chair.

\section{Authors' information}

SD is a Clinical Investigator at the Children's Hospital of Eastern Ontario (CHEO) Research Institute and Knowledge Translation Specialist with BORN Ontario; AL is an Epidemiologist with BORN Ontario; AES is the past Scientific Manager and a current Advisor to BORN Ontario; DBF is an Assistant Professor in the School of Epidemiology and Public Health at the University of Ottawa and a Scientist at the CHEO Research Institute; DW is an Epidemiologist with BORN Ontario and Adjunct Professor in the School of Epidemiology and Public Health at the University of Ottawa; JR is a Research Coordinator at the CHEO Research Institute and BORN Ontario; MT is a Biostatistician and Senior Scientist in the Clinical Epidemiology Program, Ottawa Hospital Research Institute (OHRI), and Associate Professor in the School of Epidemiology and Public Health at the University of Ottawa; EKD is a Registered Midwife, an Associate Professor in Obstetrics and Gynecology and Assistant Dean of Midwifery at McMaster University; IDG is a Senior Scientist in the OHRI and Professor in the School of Epidemiology and Public Health at the University of Ottawa; JMG is a Senior Scientist in the OHRI and coordinating editor of the Cochrane Effective Practice and Organization of Care (EPOC) group; $\mathrm{JH}$ is the Division Chief of Neonatology at CHEO and The Ottawa Hospital and is a member and the past Chair of the BORN Ontario Maternal Newborn Outcomes Committee (MNOC); GNS is the Chief of Obstetrics at Kingston General Hospital $(\mathrm{KGH})$ and a past Chair of MNOC; WEP is an Associate Professor in the School of Nursing at the University of Ottawa; MW is a Maternal-Fetal Medicine specialist and the Chief of Obstetrics Gynecology and Newborn Care at The Ottawa Hospital, Professor of Medicine at Univeristy of Ottawa, an Epidemiologist, Senior Scientist at OHRI, a co-founder of the OMNI Research Group, and the Scientific Director for BORN Ontario.

\section{Funding}

This project was funded by the Ontario Ministry of Health and Long-Term Care (Grant Number: 06684) and the Canadian Institutes of Health Research (CIHR-FRN: 133576). The funding body had no role in the design of the study, nor did they have a role in data collection, analysis, interpretation of data, or publications.

\section{Availability of data and materials}

The data analyzed during this study is held securely at the prescribed registry BORN Ontario. Data sharing regulations prevent this data from being made available publicly due to the personal health information in the datasets. Enquiries regarding BORN data must be directed to BORN Ontario (Science@BORNOntario.ca).

\section{Ethics approval and consent to participate}

Given that this re-abstraction study was a quality assurance project, it was exempt from Research Ethics Board review under article 2.5 of the Tri-council Policy Statement [29]. Permission to use BORN data for this project was obtained from BORN following completion of their formal data request process. Information about the data request process is available on the BORN website https://www.bornontario.ca/en/data/requesting-data.aspx.

\section{Consent for publication}

Not applicable.

\section{Competing interests}

The authors declare that they have no competing interests.

\section{Author details}

${ }^{1}$ Better Outcomes Registry \& Network, Ottawa, Ontario, Canada. ${ }^{2}$ Children's Hospital of Eastern Ontario Research Institute, Ottawa, Ontario, Canada. ${ }^{3}$ University of Ottawa, Ottawa, Ontario, Canada. ${ }^{4}$ The Ottawa Hospital Research Institute, Ottawa, Ontario, Canada. ${ }^{5}$ McMaster University, Hamilton, Ontario, Canada. ${ }^{6}$ Children's Hospital of Eastern Ontario, Ottawa, Ontario, Canada. ${ }^{7}$ The Ottawa Hospital, Ottawa, Ontario, Canada. ${ }^{8}$ Kingston General Hospital and Queen's University, Kingston, Ontario, Canada.

Received: 25 July 2019 Accepted: 9 December 2019

Published online: 27 December 2019

\section{References}

1. Statistics Canada. Number of births, Canada, province and territories; 2018. https://www150.statcan.gc.ca/n1/pub/91-209-x/2018001/article/54956-eng. htm . 12-12-2018. Ref Type: Electronic Citation

2. Fell DB, Sprague AE, Liu N, Yasseen AS, Smith G, Walker M. H1N1 influenza vaccination during pregnancy and fetal and neonatal outcomes. Am J Public Health. 2012;102:e33-40.

3. Gaudet L, Tu X, Fell D, El-Chaar D, Wen SW, Walker M. The effect of maternal class III obesity on neonatal outcomes: a retrospective matched cohort study. J Matern Fetal Neonatal Med. 2012;25:2281-6.

4. Dunn S, Sprague AE, Fell DB, Dy J, Harrold J, Lamontagne B, et al. The use of a quality indicator to reduce elective repeat cesarean section for low-risk women before 39 weeks' gestation: the eastern Ontario experience. J Obstet Gynecol Canada. 2013;35:306-16. 
5. Sprague AE, Dunn S, Fell D, Harrold J, Kelly S, Walker M. Measuring quality in maternal-newborn care: developing a clinical dashboard. J Obstet Gynecol Canada. 2013;35:29-38.

6. Weiss D, Dunn S, Sprague AE, Fell DB, Grimshaw J, Darling E, et al. Effect of a population-level performance dashboard intervention on maternalnewborn outcomes: an interrupted time series study. BMJ Qual Saf. 2017; 2017:1-12.

7. Sprague AE, Sidney D, Darling EK, Van Wagner V, Soderstrom B, Rogers J, et al. Outcomes for the first year of Ontario's birth Centre demonstration project. J Midwifery Women's Health. 2018;63:532-40.

8. Reszel J, Sidney D, Peterson WE, Darling EK, Van Wagner V, Soderstrom B, et al. The integration of Ontario birth Centres into existing maternal newborn services - care provider experiences. J Midwifery Women's Health. 2018;63:541-9

9. Longo C, Harrold J, Dunn S, Smith GN. Elective repeat cesarean section in low risk women - economic evaluation comparing births before versus after 39 weeks gestation in Ontario, Canada. J Obstet Gynaecol Can. 2018;40:1600-7.

10. Lanes A, Dougan S, Fell D, Huang T, Sprague AE, Johnson M, et al. Comparing maternal serum screening markers among IVG and spontaneous conceptions in Ontario through registry data. J Obstet Gynaecol Can. 2018; 40:1608-17.

11. Weiss D, Fell DB, Sprague AE, Walker MC, Dunn S, Reszel J, et al. Effect of implementation of the MOREOB program on adverse maternal and neonatal birth outcomes in Ontario, Canada: a retrospective cohort study. BMC Pregnancy Childbirth. 2019;19:1.

12. Reszel J, Dunn S, Sprague AE, Graham ID, Grimshaw JM, Peterson WE, et al. Use of a maternal newborn audit and feedback system in Ontario: a collective case study. BMJ Qual Saf. 2019;28:635-44.

13. Miao G, Fell D, Dunn S, Sprague AE. Agreement assessment of key maternal and newborn data elements between birth registry and clinical administrative hospital databases in Ontario, Canada. Arch Gynecol Obstet. 2019;1:1-9.

14. Corsi DJ, Hsu H, Weiss D, Fell DB, Walker MC. Trends and correlates of cannabis use in pregnancy: a population-based study in Ontario, Canada from 2012 to 2017. Can J Public Health. 2019;110:76-84.

15. Darling EK, Lawford KM, Wilson K, Kryanauskas M, Bourgeault I. Distance from home birth to emergency obstetrical services and neonatal outcomes: a cohort study. J Midwifery Women's Health. 2018;2018:1.

16. Darling EK, Burton N, Marquez O, Bennett N. Outcomes of uninsured people cared for by Ontario midwives: a population-based retrospective cohort study. Midwifery. 2019;2019:24-31.

17. Better Outcomes Registry \& Network (BORN) Ontario. Perinatal health reports 2009-2010 - LHIN regions. Ottawa, Ontario: BORN Ontario; 2011. https://www.bornontario.ca/en/publications//hin-regional-reports.aspx. Ref Type: Electronic Citation

18. Better Outcomes Registry \& Network (BORN Ontario). Provinical overview of perinatal health in 2011-2012. Ottawa: BORN Ontario; 2013. https://www.bornontario.ca/en/publications/resources/Documents/ Provincial-OverviewofPerinatalHealth2011-2012.pdf, 1-110. Ref Type: Electronic Citation

19. Better Outcomes Registry \& Network (BORN) Ontario. Annual report 2012 2013 and 2013-2014. Ottawa, Ontario: BORN Ontario; 2015. https://www. bornontario.ca/en/publications/resources/Documents/121187-FInal-english. pdf, 2-60. Ref Type: Electronic Citation

20. Better Outcomes Registry \& Network (BORN) Ontario. 2014-2016 biennial report. Ottawa, Ontario: BORN Ontario; 2017. https://www.bornontario.ca/ en/whats-happening/resources/Documents/Annual-report-2014-2016-DataSlides.pdf. Ref Type: Electronic Citation

21. Better Outcomes Registry \& Network (BORN Ontario). One in a million: BORN Ontario biennial report: 2016-2018; 2019. https://www.bornontario.ca/ en/publications/resources/Documents/BORN-Biennial-Report-2016-18.pdf , 1-62. Ref Type: Electronic Citation

22. Benchimol El, Smeeth L, Guttmann A, Harron K, Moher D, Petersen I, et al. The REporting of studies conducted using observational routinely-collected health data (RECORD) statement. PLoS Med. 2015;12:1-22.

23. De Coster C, Quan H, Finlayson A, Gao M, Halfon P, Humphries KH. Identifying priorities in methodological research using ICD-9-CM and ICD-10 administrative data: report from an international consortium. BMC Health Serv Res. 2006;6:77.

24. Dunn S, Bottomley J, Ali A, Walker M. Niday perinatal database quality audit: report of a quality assurance project. Chron Dis Inj Can. 2008;2011(32):21-32.
25. Better Outcomes Registry \& Network BORN Ontario. BORN data quality report executive summary 2012-2014. Ottawa, Ontario: BORN Ontario; 2016. https://www.bornontario.ca/en/data/resources/Documents/BORNData-Quality-Report-2012-2014-Executive-Summary.pdf, 1-13. Ref Type: Electronic Citation

26. Better Outcomes Registry \& Network (BORN Ontario). BORN data quality framework summary. Ottawa, Ontario: BORN Ontario; 2013. https://www. bornontario.ca/en/data/resources/Documents/BORN-Ontario-Data-QualityFramework-Summary.pdf , 1-6. Ref Type: Electronic Citation

27. Canadian Institute for Health Information. Data quality study of the 20152016 discharge abstract database: a focus on hospital harm. Ottawa: Canadian Institute for Health Information; 2016. p. 1-64. Ref Type: Report

28. Frosst G, Hutcheon J, Joseph K, Kinninburgh B, Johnson C, Lee L. Validating the British Columbia perinatal data registry: a chart re-abstraction study. BMC Pregnancy Childbirth. 2015;15:1-11.

29. Canadian Institutes of Health Research, Natural Sciences and Engineering Research Council of Canada, Social Sciences and Humanities Resaerch Council of Canada. Tri-council policy statement: ethical conduct for research involving humans; 2014. p. 1-220. December, Ref Type: Report

30. Harris PA, Taylor R, Thielke R, Payne J, Gonzalez N, Conde JG. Research electronic data capture (REDCap) - a metadata-driven methodology and workflow process for providing translational research informatics support. J Biomed Inform. 2009;42:377-81.

31. Research Electronic Data Capture (REDCap). https://www.project-redcap.org/ 2018. Ref Type: Electronic Citation.

32. Juurlink D, Preyra C, Croxford R, Chong A, Austin P, Tu J. Canadian Institute for Health Information Discharge Abstract Database: a validation study. Toronto: Institute for Clinical Evaluative Sciences; 2006. Ref Type: Report

33. Streiner DL, Norman GR. Health measurement scales: a practical guide to their development and use. 4th ed. Oxford: Oxford University Press; 2008.

34. Norman GR, Streiner DL. Biostatistics: the bare essentials. 2nd ed. Lewiston: Hamilton; 2000.

35. Bartko JJ. Measurement and reliability: statistical thinking considerations. Schizophr Bull. 1991;17:483-9.

36. Landis RJ, Koch GG. The measurement of observer agreement for categorical data. Biometrics. 1977;33:159-74.

37. Bedard M, Martin NJ, Krueger P, Brazil K. Assessing reproducibility of data obtained with instruments based on continuous measures. Exp Aging Res. 2000;26:353-65.

38. Portney LG, Watkins MP. Foundations of clinical research: applications to practice. 2nd ed. Upper Saddle River, New Jersey: Prentice-Hall; 2000.

39. Bader MD, Ailshire JA, Morenoff JD, House JS. Measurement of the local food environment: a comparison of existing data sources. Am J Epidemiol. 2010;171:609-17.

40. Joseph KS, Fahey J. Validation of perinatal data in the discharge abstract Databse of the Canadian Institute for Health Information. Chron Dis Can. 2009;9:96-100.

41. Iron K, Manuel DG. Quality assessment of administrative data (QuAAD): an opportunity for enhancing Ontario's health data. ICES investigative report. Toronto: Institute for Clinical Evaluative Sciences; 2007. Ref Type: Report

42. Hierholzer WJ. Health care data, the epidemiologist's sand: comments on the quantity and quality of data. Am J Med. 1991;91:21S-6S.

43. Fair M, Cyr M, Allen AC, Wen SW, Guyon G, MacDonald RC, et al. An assessment of the validity of a computer systsem for probablistic record linkage of birth and infant death records in Canada. Chron Dis Can. 2000;21: $1-10$.

44. Sim J, Wright CC. The kappa statistic in reliability studies: use, interpretation, and sample size requirements. Phys Ther. 2005;85:257-68.

\section{Publisher's Note}

Springer Nature remains neutral with regard to jurisdictional claims in published maps and institutional affiliations. 